\title{
Skin Hydrating Effects of Corchorus olitorius Extract in a Mouse Model of Atopic Dermatitis
}

\author{
Satoshi Yokoyama ${ }^{1 *}$, Keiichi Hiramoto ${ }^{1,2}$, Takahiko Fujikawa ${ }^{1}$, Hiroya Kondo ${ }^{3}$, Nobuyuki Konishi ${ }^{3}$, \\ Shu Sudo ${ }^{4}$, Makoto Iwashima ${ }^{1}$, Kazuya Ooi ${ }^{1}$ \\ ${ }^{1}$ Faculty of Pharmaceutical Sciences, Suzuka University of Medical Science, Mie, Japan; ${ }^{2}$ Department of Dermatology, Osaka City \\ University Graduate School of Medicine, Osaka, Japan; ${ }^{3}$ Mie Prefecture Agricultural Research Institute, Mie, Japan; ${ }^{4}$ Fundamental \\ Research Division, Research and Development Department, Mikimoto Pharmaceutical \& Co. Ltd., Mie, Japan. \\ Email: s-yoko@suzuka-u.ac.jp
}

Received December $3^{\text {rd }}$, 2013; revised January $3^{\text {rd }}$, 2014; accepted January $11^{\text {th }}, 2014$

Copyright (C) 2014 Satoshi Yokoyama et al. This is an open access article distributed under the Creative Commons Attribution License, which permits unrestricted use, distribution, and reproduction in any medium, provided the original work is properly cited. In accordance of the Creative Commons Attribution License all Copyrights @ 2014 are reserved for SCIRP and the owner of the intellectual property Satoshi Yokoyama et al. All Copyright (C) 2014 are guarded by law and by SCIRP as a guardian.

\begin{abstract}
Background: Corchorus olitorius leaf contains a significant amount of mucilaginous polysaccharide. It has been generally accepted that the polysaccharides derived from botanical extracts increase skin hydration. Since skin hydration improves skin barrier function, it is one of the most effective treatments for atopic dermatitis (AD). However, other components of botanical extracts other than polysaccharides may influence skin hydration and transepidermal water loss (TEWL). The aim of this study was to evaluate the hydration efficacy and skin barrier protection afforded to the skin after exposure to Corchorus olitorius extract without high-molecular-weight compounds (COEW), such as polysaccharides. Methods: NC/Nga mice possess disrupted skin barrier function, and were used as a model for AD. A stable base cream was supplemented with $0.2 \%$ COEW and applied to the dorsal skin of these mice. Skin hydration and TEWL were analyzed after a 14-d period of daily application. AD scores and plasma immunoglobulin E (IgE) concentrations were also investigated. Results: Compared to control mice, mice treated with the COEW cream showed significantly increased skin hydration and reduced TEWL. Plasma IgE concentrations were not affected by the COEW cream, whereas an increase in AD score in NC/Nga mice was prevented because of the application of the COEW cream. Conclusions: COEW has the ability to maintain hydration of the skin, and to prevent the disruption of skin barrier function, which leads to the aggravation of AD. COEW may be used as an adjunct treatment for AD.
\end{abstract}

\section{KEYWORDS}

\section{Corchorus olitorius; Atopic Dermatitis; Skin Hydration; Transepidermal Water Loss}

\section{Introduction}

Corchorus olitorius (C. olitorius), a member of the Tiliaceae plant family, is found in the Mediterranean region. Its tender leaves, known as moroheiya, are eaten in several countries [1]. C. olitorius leaves are rich in antioxidants such as vitamin $\mathrm{C}$, vitamin E, $\beta$-carotene, $\alpha$-tocopherol, glutathione, and phenols. The leaves also contain fatty acids, minerals, and other vitamins, and have been used as traditional folk medicine for chronic cystitis, dysuria, gonorrhea, and fever in Egypt and the Philippines

\footnotetext{
${ }^{*}$ Corresponding author.
}

[2]. In recent studies, $C$. olitorius has also been found to have antitumor and antinociceptive activities [3,4]. It is conceivable that $C$. olitorius may possess other hitherto unknown medicinal properties.

C. olitorius leaves contain a significant amount of mucilaginous polysaccharide, which is rich in uronic acid, and consists of rhamnose, glucose, galacturonic acid, and glucuronic acid [5]. Polysaccharides are known to increase skin hydration. In fact, okura polysaccharides and polysaccharides extracted from durian's fruit hulls can provide adequate skin hydration and reduce skin dryness [6,7]. Aloe vera polysaccharides also increase skin hy- 
dration levels [8]. Transepidermal water loss (TEWL) is an indicator of skin barrier function. Although Aloe vera polysaccharides can increase skin hydration, they do not affect TEWL. On the other hand, chitosan, also a polysaccharide, improves skin barrier function and reduces TEWL, but does not increase skin hydration [9]. Thus, other components of botanical extracts other than polysaccharides may influence skin hydration and TEWL. Therefore, we developed a cream formulation containing C. olitorius extract without high-molecular-weight compounds (COEW) such as polysaccharides.

The NC/Nga mouse has been extensively studied as an animal model of atopic dermatitis (AD) [10]. This mouse spontaneously develops $\mathrm{AD}$-like eczematous skin lesions when kept in conventional housing, but not when housed under specific pathogen free (SPF) conditions. Skin hydration is one of the most effective treatments known to improve AD-associated compromised skin barrier function [11]. In this study, we evaluated the hydrating effects and protective activity of COEW on the dorsal skin of the NC/Nga mouse. We also investigated the ability of COEW to prevent $\mathrm{AD}$ exacerbation.

\section{Materials and Methods}

\subsection{Experimental Animals}

Six-week-old male NC/Nga mice were purchased from Japan SLC Inc. (Shizuoka, Japan). The mice were divided into 4 groups: $\operatorname{SPF}(n=6)$, control $(n=6)$, COEW $(\mathrm{n}=6)$, and base cream $(\mathrm{BC}, \mathrm{n}=6)$. The mice in control, $\mathrm{COEW}$, and BC groups were housed under conventional conditions, while those in the SPF group were housed under SPF conditions. All mice were individually housed throughout the experiment (therefore under social isolation stress) with 1 mouse/plastic cage lined with wood chips. The animals were acclimatized under standard conditions with a 12-h light: dark cycle, constant temperature of $25^{\circ} \mathrm{C} \pm 2{ }^{\circ} \mathrm{C}$, and $50 \% \pm 10 \%$ relative humidity for $7 \mathrm{~d}$ in the animal research facility prior to commencing experimentation. All mice were allowed access to water and food ad libitum. The experimental protocol for this study was approved by the animal care regulations of Osaka City University Medical School.

\subsection{Preparation of COEW}

Dry powdered $C$. olitorius leaves were purchased from Mie Prefecture Agricultural Research Institute. This sample was extracted thrice for $48 \mathrm{~h}$ at room temperature by using acetone. To isolate the highly polar fraction, the residue was further extracted with methanol: $\mathrm{H}_{2} \mathrm{O}(2: 1)$ at $85^{\circ} \mathrm{C}$ under reflux conditions for three hours. After filtration and freeze-drying, this extract was obtained as viscous oil, and used for the formulation of the COEW cream. The COEW produced by our extraction methods de- scribed above contains few compounds over 1000 molecular weight. However, various phenols and fatty acids are contained in the COEW, which was confirmed by thin-layer chromatography.

\subsection{Formulation of the COEW Cream}

The COEW cream contained $0.2 \%$ extract of $C$. olitorius leaf in the base cream, with $\mathrm{pH}$ adjusted to approximately 6.0. Other ingredients, in order of decreasing concentration, were water, glyceryl tri (2-ethylhexanoate), acrylic acid-alkyl methacrylate copolymer, 1,3-butanediol, larginine, 1,2-dihydroxypentane, 2-hydroxyethyl phenyl ether, and hydrogenated egg yolk phospholipids (Table $1)$.

\subsection{Application of Formulations to the Dorsal Skin of Mice}

The skin on the back of each mouse was shaved with electric clippers and used as a sensitizing area. The dorsal skin of the COEW group mice was treated with $0.1 \mathrm{~g}$ of COEW cream once a day. This treatment was continued for $14 \mathrm{~d}$. Meanwhile, the dorsal skin of the BC group mice was treated with $0.1 \mathrm{~g}$ of base cream without COEW.

\subsection{Measurement of Dorsal Skin Capacitance}

The level of hydration of the outer most layer of the skin, the stratum corneum, was measured using a Corneometer $^{\circledR}$ CM825 (Courage + Khazaka Electronic GmbH, Cologne, Germany) on $14 \mathrm{~d}$ after initiation of the experiments [12]. The Corneometer probe was applied to the dorsal skin surface of each mouse. The degree of skin

Table 1. Ingredients in COEW cream and base cream.

\begin{tabular}{ccc}
\hline \multirow{2}{*}{ Ingredients } & \multicolumn{2}{c}{$(\%)$} \\
\cline { 2 - 3 } & COEW cream & Base cream \\
\hline COEW & 0.2 & - \\
Water & 52.1 & 52.3 \\
Glyceryl tri(2-ethylhexanoate) & 18.0 & 18.0 \\
Acrylic acid-alkyl methacrylate \\
copolymer \\
$\begin{array}{c}\text { 1,3-butanediol } \\
\text { L-arginine }\end{array}$ & 16.0 & 16.0 \\
$\begin{array}{c}\text { 1,2-dihydroxypentane } \\
\text { 2-hydroxyethyl phenyl ether }\end{array}$ & 3.8 & 6.8 \\
$\begin{array}{c}\text { Hydrogenated egg } \\
\text { yolk phospholipids }\end{array}$ & 0.3 & 3.5 \\
\hline
\end{tabular}

COEW: Corchorus olitorius extract without high-molecular-weight compounds. 
hydration was indicated by the electrical capacitance of the surface of the skin, and was expressed in arbitrary units (a.u.). Measurements were repeated 3 times in order to determine the hydration level of each test area, and the average was used to define the skin hydration level.

\subsection{TEWL Measurement}

TEWL was used as a marker of permeability, reflecting skin barrier function, and was measured using the Tewameter ${ }^{\circledR}$ TM300 (Courage + Khazaka Electronic GmbH, Cologne, Germany) $14 \mathrm{~d}$ after the start of the experiment [13]. Values were recorded once the responses had stabilized, which was typically $10 \mathrm{~s}$ after the probe had been placed on the skin. TEWL was measured thrice in each test area, with the average TEWL calculated from all areas tested.

\subsection{Evaluation of the Severity of Atopic Dermatitis}

Skin lesions were examined and severity was scored $14 \mathrm{~d}$ after application of each formulation. Skin lesions on the dorsal skin were assessed macroscopically according to the following 4 symptoms: erythema/hemorrhage, edema, excoriation/erosion, and scaling/dryness, and the sum was considered as the individual score ( 0 , no symptom; 1 , mild; 2, moderate; 3: severe) [14]. These visual assessments were performed by at least 2 independent investigators. Changes in the dorsal skin symptoms of the $\mathrm{NC/}$ Nga mice were evaluated by viewing photographs of the mice.

\subsection{Measurement of Plasma Immunoglobulin $\mathrm{E}$ (IgE) Concentrations}

Blood samples were drawn from mice, and plasma was separated by centrifugation at $10,000 \times \mathrm{g}$ for $10 \mathrm{~min}$ at $4{ }^{\circ} \mathrm{C}$, and stored at $-80^{\circ} \mathrm{C}$ pending analysis. Plasma IgE concentrations were measured using an enzyme-linked immunosorbent assay kit (Yamasa Shoyu Co., Ltd., Chiba, Japan) according to the manufacturers' instructions. The optical density was measured with a microplate reader.

\subsection{Statistical Analysis}

All data are presented as the mean \pm S.D. Comparisons between the 4 groups were performed using a one-way analysis of variance, with Tukey's test for multiple comparisons used for post hoc analysis. $P$ values of $<0.05$ were defined as statistically significant.

\section{Results}

\subsection{Quantitative Assessment of Skin Hydration}

The skin hydration levels $14 \mathrm{~d}$ after daily application of
COEW cream or base cream are shown in Figure 1. The skin hydration level of the SPF group, in which no cream was applied, was $68.3 \pm 8.85$ arbitrary unit (a.u.). Compared to the SPF group, the control group and BC group showed significantly decreased skin hydration levels, respectively $(p<0.01)$. The skin hydration level in COEW group was significantly higher than that in the control group and $\mathrm{BC}$ group ( $p<0.01, p<0.05$, respectively). Further, there was no significant difference in the skin hydration level between in the SPF group and in the COEW group. The skin hydration level in the BC group decreased to a similar extent as that in the control group. These results showed that COEW prevented a significant reduction in skin hydration.

\subsection{Quantitative Assessment of TEWL}

Figure 2 shows the TEWL after a $14 \mathrm{~d}$ application of formulations. TEWL in the SPF group was $8.48 \pm 0.37$ $\left(\mathrm{g} / \mathrm{m}^{2} / \mathrm{h}\right)$. We observed a significant increase in TEWL in the control group relative to the SPF group $(p<0.01)$. TEWL in the COEW group was significantly reduced compared to that in the control group $(p<0.01)$. TEWL in the $\mathrm{BC}$ group was also reduced compared to that in the control group $(p<0.01)$. However, TEWL in the BC group was significantly higher than that in the SPF group $(p<0.01)$. There was no significant difference in the TEWL between the COEW and SPF groups.

\subsection{Evaluation of the Severity of AD}

Figure 3 shows the evaluation of the severity of AD. At the start of this experiment, the $\mathrm{AD}$ scores among the 4 groups were 0 . After $14 \mathrm{~d}$, the AD score in the SPF group

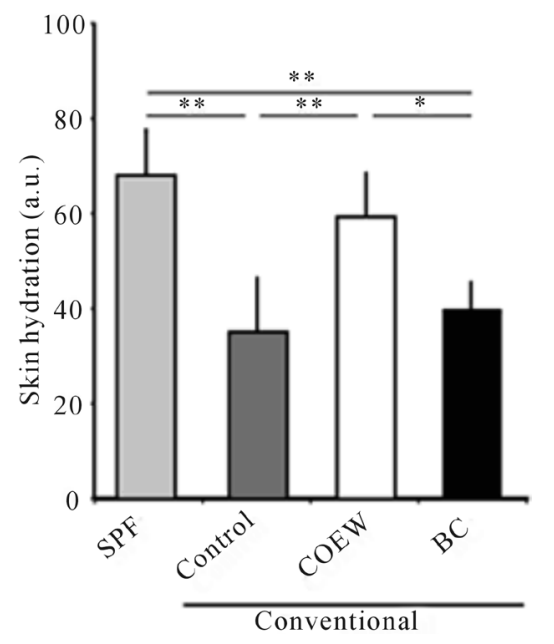

Figure 1. Skin hydration levels in the SPF, control, COEW, and BC groups following a $14 \mathrm{~d}$ period of daily application. SPF: specific pathogen free, COEW: Corchorus olitorius extract without high molecular weight compounds, BC: treated with the base cream, a.u.; arbitrary unit, ${ }^{*} p<0.05$, ${ }^{* *} p<0.01$, each group, $n=6$. 


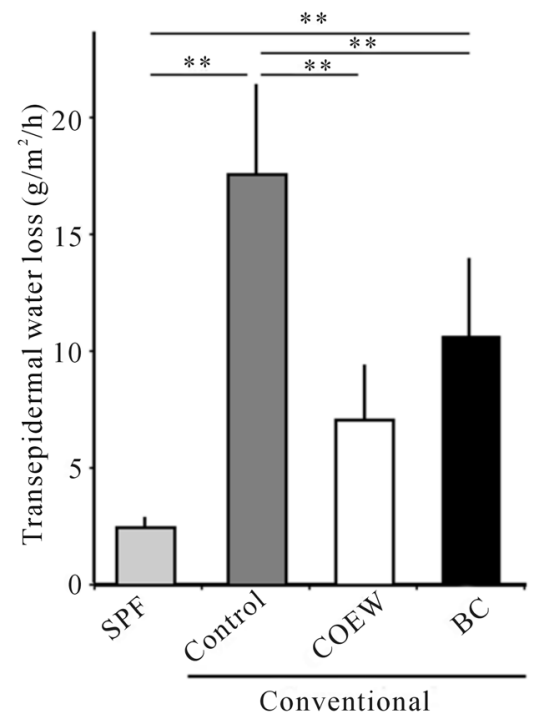

Figure 2. Transepidermal water loss in the SPF, control, COEW, and BC groups following a $14 \mathrm{~d}$ period of daily application. SPF: specific pathogen free, COEW: Corchorus olitorius extract without high molecular weight compounds, BC: treated with the base cream, ${ }^{* *} p<0.01$, each group, $n=$ 6.

(a) Start
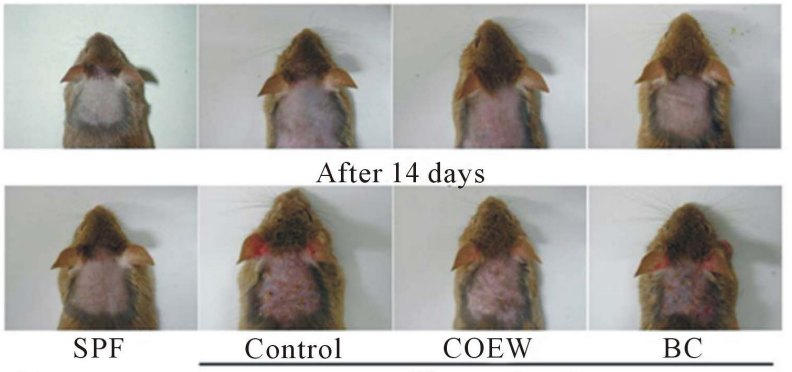

(b)

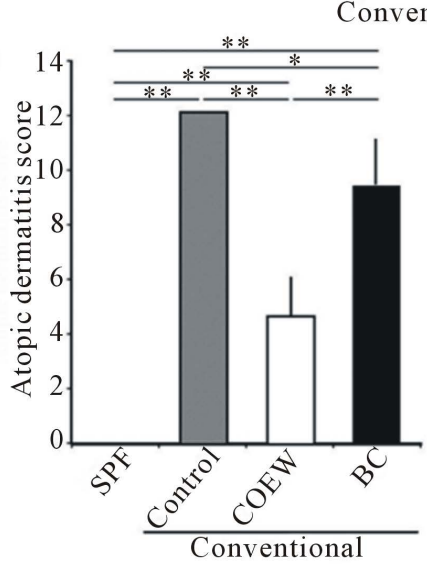

Figure 3. Skin symptoms and atopic dermatitis scores in SPF, control, COEW, and BC groups of NC/Nga mice. (a) Skin symptoms before and after a $14 \mathrm{~d}$ period of daily application. (b) Atopic dermatitis scores after a $14 \mathrm{~d}$ period of daily application. SPF: specific pathogen free, COEW: Corchorus olitorius extract without high molecular weight compounds, BC: treated with the base cream, ${ }^{*} p<0.05,{ }^{* *} p$ $<0.01$, each group, $n=6$. was 0 , whereas that in control group increased (AD score $=12$ ). In contrast, the $\mathrm{AD}$ score in COEW group (AD score $=4.7 \pm 1.5)$ and $\mathrm{BC}$ group $(\mathrm{AD}$ score $=9.3 \pm 1.9)$ significantly reduced compared with that in the control group ( $p<0.01, p<0.05$, respectively). Further, the AD score in the COEW group reduced compared to that of the $\mathrm{BC}$ group $(p<0.01)$.

\subsection{Influence of Formulations on Plasma IgE Concentrations}

Plasma IgE concentrations in the SPF group were at the lower limits of detection $14 \mathrm{~d}$ after the start of the paradigm, whereas the plasma IgE concentrations in the other 3 groups significantly increased (Figure 4). The plasma IgE concentrations in the control, COEW treated, and BC treated groups were $8593 \pm 670.8,8026 \pm 929.5$, and $8091 \pm 738.4 \mathrm{ng} / \mathrm{mL}$, respectively. There were no significant differences between the three groups.

\section{Discussion}

In recent studies, examining the relationship between the use of botanical extracts and skin hydration, formulations including okura polysaccharide or polysaccharide from the root bark of Ulmus davidiana (var. japonica) retained skin hydration $[6,15]$. In our study, COEW also retained adequate levels of skin hydration. However, this efficacy was not related to polysaccharide content because highmolecular-weight compounds like polysaccharides were extracted from $C$. olitorius leaves. With the exception of the polysaccharides, the fatty acids present in botanical extracts are known to facilitate the hydration of skin.

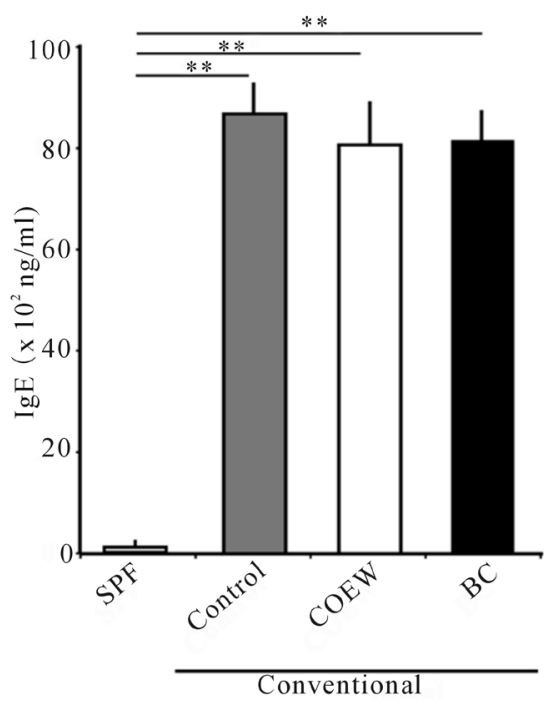

Figure 4. Plasma IgE concentrations in SPF, control, COEW, and BC groups after a $14 \mathrm{~d}$ period of daily application. SPF: specific pathogen free, COEW: Corchorus olitorius extract without high molecular weight compounds, BC: treated with the base cream, ${ }^{* *} p<0.01$, each group, $n=6$. 
Sunflower oil contains high-concentrations of essential fatty acids, particularly linoleic acid, which enhances skin hydration. In fact, one formulation containing $2 \%$ sunflower oleodistillate significantly increased the degree of skin hydration [16]. C. olitorius leaves also have a high fatty acid content, especially alpha-linorenic acid and linoleic acid [2]. Further, they have the ability to exert anti-inflammatory effects [17], which prevent the disruption of the skin barrier function [18]. Thus, the retention of skin hydration in our study might be related to the fatty acids content of our formulations.

We quantitated TEWL, because disturbances in the function of the epidermal barrier results in decreased skin hydration, increased TEWL, and the development of dry skin. Oxidative stress is one condition that leads to disruption of skin barrier function [19]. Reactive oxygen species (ROS) are the most important components of the oxidative system. ROS may act as second messengers in biological processes and play a triggering role in the pathogenesis of allergic reactions and inflammation of the skin. They cause lipid peroxidation in the cell membrane and secretion of inflammatory cytokines, which together elicit an inflammatory response. Therefore, suppressing activation of ROS protects skin barrier function and maintains skin hydration levels. C. olitorius was found to contain high quantities of antioxidant molecules [2]. Our results indicated that TEWL in the control group increased markedly compared to the SPF group, whereas TEWL in the COEW group was significantly decreased compared to the control group. Antioxidants present in the extract of $C$. olitorius might prevent the disruption of skin barrier function and lead to retention of adequate skin hydration levels.

IgE has been recognized to be important factor in atopic dermatitis. In the control group under the conventional conditions, plasma IgE concentrations increased markedly compared to the SPF group. In the other conventional groups, plasma IgE concentrations also increased. However, AD score in the COEW group was significantly reduced than that in the control group. In the aggravation of atopic dermatitis in NC/Nga mice, COEW does not seem to affect the plasma IgE concentrations. In the recent study, while the $\mathrm{AD}$ score was suppressed in conventional NC/Nga mice, plasma IgE concentrations was maintained to high levels [20], which phenomenon supports our data.

In an earlier report, Yoshikawa et al. showed that the extract from $C$. olitorius leaves had an inhibitory effect on histamine release [21]. Histamine is one of the proinflammatory factors of AD. Moreover, C. olitorius contains significant amounts of vitamin $\mathrm{E}$ and vitamin $\mathrm{B}_{3}$ [2]. It has previously been reported that vitamin $\mathrm{E}$ improved the symptoms of $\mathrm{AD}$ by decreasing the concentrations of inflammatory factors [22], and that nicotinamide, which is the amide of vitamin $B_{3}$, promoted a decrease in TEWL on atopic dry skin [23]. These compounds may play a role in the observed efficacy of COEW on ADlike inflammation. Further study is needed in order to elucidate which compounds are playing important functional roles, and the detailed mechanism of COEW action.

\section{Conclusion}

COEW protected the barrier function of the skin by maintaining adequate skin hydration, causing a reduction of TEWL in NC/Nga mice. Further, COEW suppressed an increase in the AD score in NC/Nga mice despite a lack of influence on plasma IgE concentrations. It may be used as an adjunct treatment for $\mathrm{AD}$, potentially improving $\mathrm{AD}$ therapy.

\section{REFERENCES}

[1] A. F. Abu-Hadid, M. Z. El-Shinawy, A. S. El-Bethagy, S. A. Gaafer and M. Medany, "Studies on the Production of Off-Season Jew’s Mallow (Molokhia) in Egypt,” Egyptian Journal of Horticulture, Vol. 21, 1994, pp. 187-193.

[2] S. Zeghichi, S. Kallithraka and A. P. Simopoulos, "Nutritional Composition of Molokhia (Corchorus olitorius) and Stamnagathi (Cichorium spinosum)," World Review of Nutrition \& Dietetics, Vol. 91, 2003, pp. 1-21. http://dx.doi.org/10.1159/000069924

[3] Z. A. Zakaria, M. Safarul, R. Valsala, M. R. Sulaiman, C. A. Fatimah, M. N. Somchit and A. M. Mat Jais, "The Influences of Temperature and Naloxone on the Antinociceptive Activity of Corchorus olitorius L. in Mice," Naunyn-Schmiedeberg's Archives of Pharmacology, Vol. 372, No. 1, 2005, pp. 55-62. http://dx.doi.org/10.1007/s00210-005-1089-8

[4] C. J. Li, S. Y. Huang, M. Y. Wu, Y. C. Chen, S. F. Tsang, J. H. Chyuan and H. Y. Hsu, "Induction of Apoptosis by Ethanolic Extract of Corchorus olitorius Leaf in Human Hepatocellular Carcinoma (HepG2) Cells via a Mitochondria-Dependent Pathway," Molecules, Vol. 17, No. 8, 2012, pp. 9348-9360. http://dx.doi.org/10.3390/molecules17089348

[5] K. Ohtani, K. Okai, U. Yamashita, I. Yuasa and A. Misaki, "Characterization of an Acidic Polysaccharide Isolated from the Leaves of Corchorus olitorius (Moroheiya)," Bioscience, Biotechnology, and Biochemistry, Vol. 59, No. 3, 1995, pp. 378-381.

http://dx.doi.org/10.1271/bbb.59.378

[6] M. Kanlayavattanakul, C. Rodchuea and N. Lourith, "Moisturizing Effect of Alcohol-Based Hand Rub Containing Okra Polysaccharide," International Journal of Cosmetic Science, Vol. 34, No. 3, 2012, pp. 280-283. http://dx.doi.org/10.1111/j.1468-2494.2012.00715.x

[7] B. Futrakul, M. Kanlayavattanakul and P. Krisdaphong, "Biophysic Evaluation of Polysaccharide Gel from Durian's Fruit Hulls for Skin Moisturizer,” International Journal of Cosmetic Science, Vol. 32, No. 3, 2010, pp. 
211-215. http://dx.doi.org/10.1111/j.1468-2494.2009.00552.x

[8] S. E. Dal’Belo, L. R. Gaspar and P. M. Maia Campos, "Moisturizing Effect of Cosmetic Formulations Containing Aloe Vera Extract in Different Concentrations Assessed by Skin Bioengineering Techniques," Skin Research and Technology, Vol. 12, No. 4, 2006, pp. 241246. http://dx.doi.org/10.1111/j.0909-752X.2006.00155.x

[9] M. Fujii, T. Shimizu, T. Nakamura, F. Endo, S. Kohno and T. Nabe, "Inhibitory Effect of Chitosan-Containing Lotion on Scratching Response of Hairless Mice with Atopic Dermatitis-Like Dry Skin,” Bioscience, Biotechnology, and Biochemistry, Vol. 34, No. 12, 2011, pp. 1890-1894. http://dx.doi.org/10.1248/bpb.34.1890

[10] A. Aioi, H. Tonogaito, H. Suto, K. Hamada, C. R. Ra, H. Ogawa, H. Maibach and H. Matsuda, "Impairment of Skin Barrier Function in NC/Nga Tnd Mice as a Possible Model for Atopic Dermatitis," British Journal of Dermatology, Vol. 144, No. 1, 2001, pp. 12-18. http://dx.doi.org/10.1046/j.1365-2133.2001.03946.x

[11] M. Lodén, A. C. Andersson and M. Lindberg, "Improvement in Skin Barrier Function in Patients with Atopic Dermatitis after Treatment with a Moisturizing Cream (Canoderm)," British Journal of Dermatology, Vol. 140, No. 2, 1999, pp. 264-267.

http://dx.doi.org/10.1046/j.1365-2133.1999.02660.x

[12] E. Berardesca and European Group for Efficacy Measurements on Cosmetics and Other Topical Products (EEMCO), "EEMCO Guidance for the Assessment of Stratum Corneum Hydration: Electrical Methods,” Skin Research and Technology, Vol. 3, No. 2, 1997, pp. 126132. http://dx.doi.org/10.1111/j.1600-0846.1997.tb00174.x

[13] A. O. Barel and P. Clarys, "Study of the Stratum Corneum Barrier Function by Transepidermal Water Loss Measurements: Comparison between Two Commercial Instruments: Evaporimeter and Tewameter," Skin Pharmacology, Vol. 8, No. 4, 1995, pp. 186-195. http://dx.doi.org/10.1159/000211345

[14] D. Y. Leung, R. L. Hirsch, L. Schneider, C. Moody, R. Takaoka, S. H. Li, L. A. Meyerson, S. G. Mariam, G. Goldstein and J. M. Hanifin, "Thymopentin Therapy Reduces the Clinical Severity of Atopic Dermatitis,” Journal of Allergy and Clinical Immunology, Vol. 85, No. 5, 1990, pp. 927-933. http://dx.doi.org/10.1016/0091-6749(90)90079-J

[15] S. Y. Eom, C. B. Chung, Y. S. Kim, J. H. Kim, K. S. Kim, Y. H. Kim, S. H. Park, Y. I. Hwang and K. H. Kim, "Cosmeceutical Properties of Polysaccharides from the
Root Bark of Ulmus davidiana var. Japonica,” Journal of Cosmetic Science, Vol. 57, No. 5, 2006, pp. 355-367.

[16] L. F. Eichenfield, A. McCollum and P. Msika, “The Benefits of Sunflower Oleodistillate (SOD) in Pediatric Dermatology,” Pediatric Dermatology, Vol. 26, No. 6, 2009, pp. 669-675.

http://dx.doi.org/10.1111/j.1525-1470.2009.01042.x

[17] M. M. McCusker and J. M. Grant-Kels, "Healing Fats of the Skin: The Structural and Immunologic Roles of the Omega-6 and Omega-3 Fatty Acids," Clinics in Dermatology, Vol. 28, No. 4, 2010, pp. 440-451. http://dx.doi.org/10.1016/j.clindermatol.2010.03.020

[18] C. H. Yen, Y. S. Dai, Y. H. Yang, L. C. Wang, J. H. Lee and B. L. Chiang, "Linoleic acid Metabolite Levels and Transepidermal Water Loss in Children with Atopic Dermatitis," Annals of Allergy, Asthma \& Immunology, Vol. 100, No. 1, 2008, pp. 66-73.

http://dx.doi.org/10.1016/S1081-1206(10)60407-3

[19] K. Nakai, K. Yoneda and Y. Kubota, "Oxidative Stress in Allergic and Irritant Dermatitis: From Basic Research to Clinical Management," Recent Patents on Inflammation \& Allergy Drug Discovery, Vol. 6, No. 3, 2012, pp. 202209. http://dx.doi.org/10.2174/187221312802652839

[20] K. Orita, K. Hiramoto, R. Inoue, E. F. Sato, H. Kobayashi, M. Ishii and M. Inoue, "Strong Exercise Stress Exacerbates Dermatitis in Atopic Model Mice, NC/Nga Mice, while Proper Exercise Reduces It," Experimental Dermatology, Vol. 19, No. 12, 2010, pp. 1067-1072. http://dx.doi.org/10.1111/j.1600-0625.2010.01130.x

[21] M. Yoshikawa, H. Shimada, M. Saka, S. Yoshizumi, J. Yamahara and H. Matsuda, "Medicinal Foodstuffs. V. Moroheiya. (1): Absolute Stereostructures of Corchoionosides A, B, and C, Histamine Release Inhibitors from the Leaves of Vietnamese Corchorus olitorius L. (Tiliaceae)," Chemical \& Pharmaceutical Bulletin, Vol. 45, No. 3, 1997, pp. 464-469. http://dx.doi.org/10.1248/cpb.45.464

[22] D. Hayashi, H. Sugaya, T. Ohkoshi, K. Sekizawa, H. Takatsu, T. Shinkai and S. Urano, "Vitamin E Improves Biochemical Indices Associated with Symptoms of Atopic Dermatitis-Like Inflammation in NC/Nga Mice,” Journal of Nutritional Science and Vitaminology, Vol. 58, No. 3, 2012, pp. 161-168. http://dx.doi.org/10.3177/jnsv.58.161

[23] Y. Soma, M. Kashima, A. Imaizumi, H. Takahama, T. Kawakami and M. Mizoguchi, "Moisturizing Effects of Topical Nicotinamide on Atopic Dry Skin,” International Journal of Dermatology, Vol. 44, No. 3, 2005, pp. 197202. http://dx.doi.org/10.1111/j.1365-4632.2004.02375.x 